Invited

\title{
E-Iron Oxide Exhibiting High-Frequency Millimeter Wave Absorption
}

\author{
M. YOSHIKIYO ${ }^{\text {a) }}$, A. NAMAI ${ }^{\text {a) }}$, and S. OHKOSHI ${ }^{\text {a) }}$,b),*
}

a) Department of Chemistry, School of Science, The University of Tokyo, 7-3-1 Hongo, Bunkyo-ku, Tokyo 113-0033, Japan

b) CREST, JST, K's Gobancho, 7 Gobancho, Chiyoda-ku, Tokyo 102-0076, Japan

\section{Abstract}

This review article describes the large coercive field and high frequency millimeter wave absorption of $\varepsilon-\mathrm{Fe}_{2} \mathrm{O}_{3}$. In 2004, we obtained pure $\varepsilon-\mathrm{Fe}_{2} \mathrm{O}_{3}$ phase by a particular chemical synthesis method for nanosize particles, a combination method of reverse-micelle and sol-gel techniques. This $\varepsilon-\mathrm{Fe}_{2} \mathrm{O}_{3}$ exhibits a huge coercive field of $20 \mathrm{kOe}$ at room temperature. In addition, its physical properties can be widely controlled by substituting the iron cations with other metal cations. In this paper, the synthesis, crystal structure, magnetic properties, and especially, the millimeter wave absorption properties of $\varepsilon-\mathrm{Fe}_{2} \mathrm{O}_{3}$ and metal substituted $\varepsilon-\mathrm{Fe}_{2} \mathrm{O}_{3}, \varepsilon-M_{x} \mathrm{Fe}_{2-x} \mathrm{O}_{3}(M=\mathrm{Al}$ and $\mathrm{Ga}$ ) are presented. $\varepsilon-\mathrm{Fe}_{2} \mathrm{O}_{3}$ and $\varepsilon-M_{x} \mathrm{Fe}_{2-x} \mathrm{O}_{3}$ based magnets have the possibility as millimeter wave absorbers for the future high-speed wireless communications.

Key Words: $\varepsilon-\mathrm{Fe}_{2} \mathrm{O}_{3}$, Iron oxide, Hard magnet, Millimeter wave

\section{INTRODUCTION}

Maghemite $\left(\gamma-\mathrm{Fe}_{2} \mathrm{O}_{3}\right)$ and hematite $\left(\alpha-\mathrm{Fe}_{2} \mathrm{O}_{3}\right)$ of iron oxide $\mathrm{Fe}_{2} \mathrm{O}_{3}$ are commonly observed in nature and have been extensively studied [1-8]. $\gamma-\mathrm{Fe}_{2} \mathrm{O}_{3}$ has been used in magnetic recording tapes or magnetic fluids, while $\alpha-\mathrm{Fe}_{2} \mathrm{O}_{3}$ is widely known as red-dye. In the case of bulk $\mathrm{Fe}_{2} \mathrm{O}_{3}, \gamma-\mathrm{Fe}_{2} \mathrm{O}_{3}$ is known to transform to $\alpha-\mathrm{Fe}_{2} \mathrm{O}_{3}$ with increasing temperature. By chemical synthesis of $\mathrm{Fe}_{2} \mathrm{O}_{3}$ nanoparticles, our group obtained a pure phase of $\varepsilon-\mathrm{Fe}_{2} \mathrm{O}_{3}$ (Fig. 1a) [9-11]. Its crystal structure is totally different from those of $\gamma-\mathrm{Fe}_{2} \mathrm{O}_{3}$ or $\alpha-\mathrm{Fe}_{2} \mathrm{O}_{3}$. In 2004, we reported that $\varepsilon-\mathrm{Fe}_{2} \mathrm{O}_{3}$ has an extremely large coercive field $\left(H_{\mathrm{c}}\right)$ of $20 \mathrm{kOe}$ at room temperature, which is the largest among metal oxide-based magnets (Fig. 1b). Another interesting feature of $\varepsilon-\mathrm{Fe}_{2} \mathrm{O}_{3}$ is that it shows a spin reorientation phenomenon at $115 \mathrm{~K}$ [12-15]. From these unique magnetic properties, various experimental researches, such as Mössbauer studies, neutron diffraction studies, $\mathrm{X}$-ray magnetic circular dichroism studies, etc. have been conducted to date [16-18]. Moreover, we have reported that $\varepsilon-\mathrm{Fe}_{2} \mathrm{O}_{3}$ exhibits high frequency millimeter wave absorption at $182 \mathrm{GHz}$ [19], which is due to zero-field ferromagnetic resonance. The absorption frequency was widely changed by metal substitution of $\mathrm{Fe}^{3+}$ ions [19-21].

Fig 1. (a) Phase transformation of $\mathrm{Fe}_{2} \mathrm{O}_{3}$ and crystal structures of $\gamma-\mathrm{Fe}_{2} \mathrm{O}_{3}, \alpha-\mathrm{Fe}_{2} \mathrm{O}_{3}$, and $\varepsilon-\mathrm{Fe}_{2} \mathrm{O}_{3}$. (b) Magnetization versus external magnetic field curve of $\varepsilon-\mathrm{Fe}_{2} \mathrm{O}_{3}$ at $300 \mathrm{~K}$ exhibiting an $H_{\mathrm{c}}$ value of $20 \mathrm{kOe}$, adapted from ref [9].

(a)

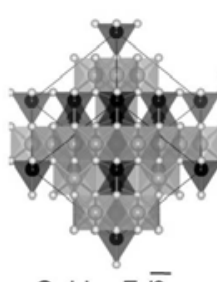

Cubic, $F d \overline{3} m$
Phase transformation $-\mathrm{Fe}_{2} \mathrm{O}_{3}-\mathrm{in}$ bulk form $--\rightarrow \alpha-\mathrm{Fe}_{2} \mathrm{O}_{3}$
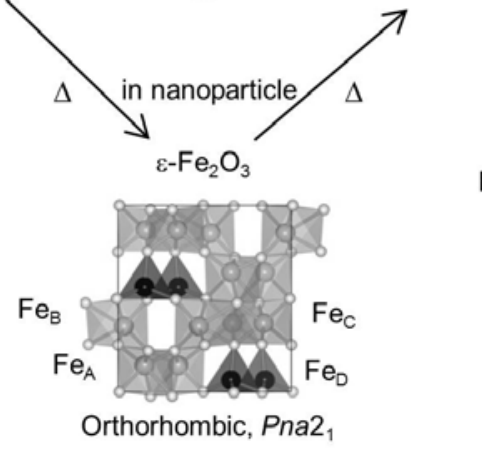

(b)

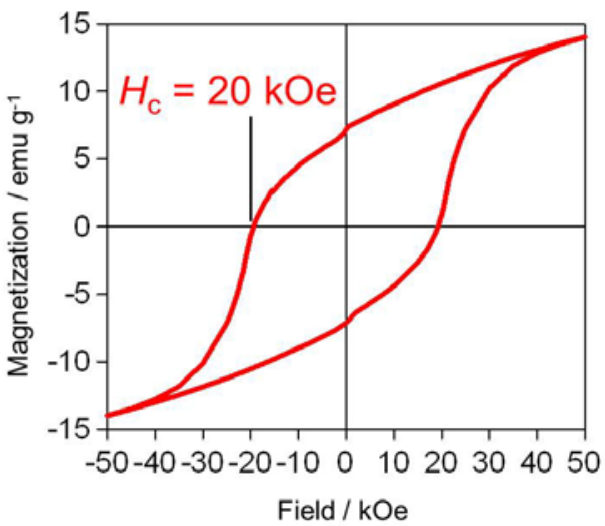




\section{SYNTHESIS}

$\varepsilon-\mathrm{Fe}_{2} \mathrm{O}_{3}$ and metal substituted $\varepsilon-\mathrm{Fe}_{2} \mathrm{O}_{3}\left(\varepsilon-M_{x} \mathrm{Fe}_{2-x} \mathrm{O}_{3}, M=\mathrm{Al}\right.$ and $\left.\mathrm{Ga}\right)$ nanoparticles are synthesized by chemical methods such as combination of reverse-micelle and sol-gel techniques, sol-gel method, and impregnation method using mesoporous silica [9,10,19-24]. Here, the combination method of reverse-micelle and solgel methods is described (Fig. 2a). In the reverse-micelle step, two reverse-micelle systems are formed by cetyl trimethyl ammonium bromide (CTAB) and 1-butanol as surfactant in n-octane solvent. One reverse-micelle system contains aqueous solution of $\mathrm{Fe}\left(\mathrm{NO}_{3}\right)_{3}$ and $\mathrm{Ba}\left(\mathrm{NO}_{3}\right)_{2}$ with addition of $\mathrm{Al}\left(\mathrm{NO}_{3}\right)_{3}$ or $\mathrm{Ga}\left(\mathrm{NO}_{3}\right)_{3}$ for metal substituted series, and the other contains $\mathrm{NH}_{3}$ aqueous solution. These two microemulsion systems are mixed under rapid stirring, and tetraethoxysilane $\left(\mathrm{C}_{2} \mathrm{H}_{5} \mathrm{O}\right)_{4} \mathrm{Si}$ is successively added to this solution. This forms $\mathrm{SiO}_{2}$ matrix around the $\mathrm{M}_{x} \mathrm{Fe}_{2-x}(\mathrm{OH})_{6}$ nanoparticles to obtain the precursor nanoparticles. The precipitation is separated by centrifugation and sintered in air at $1000^{\circ} \mathrm{C}$ for 4 hours. The $\mathrm{SiO}_{2}$ matrix is removed by stirring in $\mathrm{NaOH}$ solution at $60^{\circ} \mathrm{C}$ for 24 hours. With this synthesis method, rod-shaped $\varepsilon-M_{x} \mathrm{Fe}_{2-x} \mathrm{O}_{3}$ is obtained due to the effect of $\mathrm{Ba}^{2+}$ ions, which adsorb on particular planes of $\varepsilon-\mathrm{Fe}_{2} \mathrm{O}_{3}$ as morphology control agent, inducing growth towards one direction (Fig. 2b). Spherical nanoparticles can also be obtained without the use of $\mathrm{Ba}\left(\mathrm{NO}_{3}\right)_{2}$ (Fig. 2c).

(a)

$$
\begin{aligned}
& \left\{\begin{array}{l}
\mathrm{Fe}\left(\mathrm{NO}_{3}\right)_{3} \text { aq. } \\
M\left(\mathrm{NO}_{3}\right)_{3} \text { aq. }
\end{array}\right. \\
& \text { ( } M=\mathrm{Al}, \mathrm{Ga})
\end{aligned}
$$

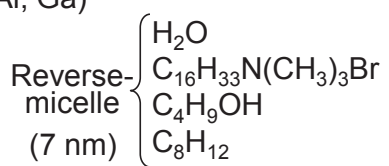$$
M_{x} \mathrm{Fe}_{2-x}(\mathrm{OH})_{6}
$$$$
(5 \mathrm{~nm})
$$$$
\text { Sol-gel method }
$$

3. Sintering

$$
\underset{\text { air }}{\Delta} \longrightarrow \varepsilon-M_{x} \mathrm{Fe}_{2-x} \mathrm{O}_{3} / \mathrm{SiO}_{2}
$$

\section{Removal of $\mathrm{SiO}_{2}$} $\mathrm{NaOH}$ aq. (b)

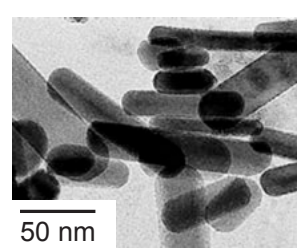

(c)

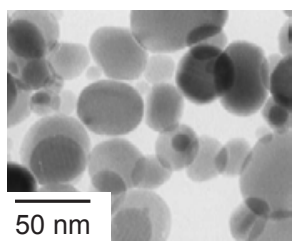

Fig. 2 (a) Synthesis scheme of $\varepsilon-M_{x} \mathrm{Fe}_{2-x} \mathrm{O}_{3}$. (b) TEM image of rod-shaped $\varepsilon-\mathrm{Ga}_{0.43} \mathrm{Fe}_{1.57} \mathrm{O}_{3}$ adapted from ref [24] and (c) spherical $\varepsilon-\mathrm{Ga}_{0.40} \mathrm{Fe}_{1.60} \mathrm{O}_{3}$ adapted from ref [20].

\section{CRYSTAL STRUCTURE}

$\varepsilon-\mathrm{Fe}_{2} \mathrm{O}_{3}$ has an orthorhombic crystal structure ( $a=5.1019$ (3) $\AA, b=8.7807$ (6) $\AA, c=9.4661$ (5) $\AA$ ), categorized in $P n a 2_{1}$ space group with spontaneous polarization [12]. There are four different $\mathrm{Fe}^{3+}$ sites, $\mathrm{Fe}_{\mathrm{A}}, \mathrm{Fe}_{\mathrm{B}}, \mathrm{Fe}_{\mathrm{C}}$, and $\mathrm{Fe}_{\mathrm{D}}$, where $\mathrm{Fe}_{\mathrm{A}}, \mathrm{Fe}_{\mathrm{B}}$, and $\mathrm{Fe}_{\mathrm{C}}$ are octahedral, and $\mathrm{Fe}_{\mathrm{D}}$ is tetrahedral coordination (Fig. 1a). The bond lengths of $\mathrm{Fe}$ and $\mathrm{O}$ are $1.87-$ $2.43 \AA$ for $\mathrm{Fe}_{\mathrm{A}}-\mathrm{O}, 1.73-2.38 \AA$ for $\mathrm{Fe}_{\mathrm{B}}-\mathrm{O}, 1.86-2.21 \AA$ for $\mathrm{Fe}_{\mathrm{C}}-\mathrm{O}$, and $1.74-1.94 \AA$ for $\mathrm{Fe}_{\mathrm{D}}-\mathrm{O}$, indicating largely distorted coordination geometries around $\mathrm{Fe}_{\mathrm{A}}$ and $\mathrm{Fe}_{\mathrm{B}}$ sites. The $\mathrm{Al}$ substituted and $\mathrm{Ga}$ substituted samples also have the same orthorhombic crystal structure. Rietveld analyses of the X-ray diffraction patterns showed that non-magnetic $\mathrm{Al}^{3+}$ ions and $\mathrm{Ga}^{3+}$ ions selectively occupy the $\mathrm{Fe}_{\mathrm{D}}$ site among the four iron sites (Table I). This site selectivity is understood by the smaller ion radius of $\mathrm{Al}^{3+}(0.535 \AA)$ and $\mathrm{Ga}^{3+}(0.620 \AA)$ compared to $\mathrm{Fe}^{3+}(0.645 \AA)$ [25]. The $\mathrm{Al}^{3+}$ and $\mathrm{Ga}^{3+}$ ions prefer to occupy the smaller tetrahedral $\mathrm{Fe}_{\mathrm{D}}$ site than the octahedral $\mathrm{Fe}_{\mathrm{A}}, \mathrm{Fe}_{\mathrm{B}}$, and $\mathrm{Fe}_{\mathrm{C}}$ sites.

\section{MAGNETIC PROPERTIES}

$\varepsilon-\mathrm{Fe}_{2} \mathrm{O}_{3}$ shows spontaneous magnetization at a Curie temperature $\left(T_{\mathrm{C}}\right)$ of about $500 \mathrm{~K}$. At room temperature, $\varepsilon-\mathrm{Fe}_{2} \mathrm{O}_{3}$ shows a huge magnetic hysteresis loop as shown in Fig. 1b. The $H_{\mathrm{c}}$ value of $\varepsilon-\mathrm{Fe}_{2} \mathrm{O}_{3}$ at $300 \mathrm{~K}$ is $20 \mathrm{kOe}$. The magnetic structure has been investigated using molecular field theory, which indicated that $\varepsilon-\mathrm{Fe}_{2} \mathrm{O}_{3}$ is a ferrimagnet, where $\mathrm{Fe}_{\mathrm{B}}$ and $\mathrm{Fe}_{\mathrm{C}}$ sites have positive sublattice magnetizations, and $\mathrm{Fe}_{\mathrm{A}}$ and $\mathrm{Fe}_{\mathrm{D}}$ sites have negative sublattice magnetizations (Fig. 3a) [26]. This result was consistent with the experimental results from neutron diffraction measurements and Mössbauer spectroscopy measurements [14,18], and was also consistent with first-principles calculation results [27]. 
Table I Substitution ratios (\%) of each Fe site for $\varepsilon-\mathrm{Ga}_{x} \mathrm{Fe}_{2-x} \mathrm{O}_{3}$ and $\varepsilon-\mathrm{Al}_{x} \mathrm{Fe}_{2-x} \mathrm{O}_{3}[19,20]$.

\begin{tabular}{llllll}
\hline & $x$ & $\mathrm{Fe}_{\mathrm{A}}$ & $\mathrm{Fe}_{\mathrm{B}}$ & $\mathrm{Fe}_{\mathrm{C}}$ & $\mathrm{Fe}_{\mathrm{D}}$ \\
\hline \hline Ga substitution & 0.10 & 0 & 0 & 8 & 12 \\
& 0.22 & 0 & 0 & 9 & 35 \\
& 0.29 & 0 & 0 & 13 & 45 \\
& 0.40 & 0 & 0 & 17 & 63 \\
& 0.54 & 0 & 8 & 21 & 79 \\
& 0.67 & 0 & 9 & 28 & 98 \\
\hline \multirow{2}{*}{ Al substitution } & 0.06 & 3 & 0 & -2 & 11 \\
& 0.09 & 3 & -1 & -1 & 17 \\
& 0.21 & 0 & 3 & 8 & 30 \\
& 0.30 & 10 & 2 & 11 & 38 \\
& 0.40 & 12 & 1 & 14 & 52 \\
\hline
\end{tabular}

By increasing the $\mathrm{Ga}^{3+}$ and $\mathrm{Al}^{3+}$ substitution ratio, change of the magnetic properties was observed. The field-cooled magnetization curves under an external magnetic field of 10 Oe showed that the $T_{\mathrm{C}}$ value decreased from $500 \mathrm{~K}(x=0)$ to $448 \mathrm{~K}(\mathrm{Al}, x=0.40)$ and $324 \mathrm{~K}(\mathrm{Ga}, x=0.67)$ with the increase of substitution. As for the $H_{\mathrm{c}}$ value at $300 \mathrm{~K}$, it decreased from $22.5 \mathrm{kOe}(x=0)$ to $10.2 \mathrm{kOe}(x=0.40)$ with $\mathrm{Al}$ substitution, and saturation magnetization $\left(M_{\mathrm{s}}\right)$ value increased. Similarly, with Ga substitution, the $H_{\mathrm{c}}$ value decreased to $2.1 \mathrm{kOe}(x=0.67)$ and $M_{\mathrm{s}}$ value increased (Fig. 3b). These changes in the magnetic properties can be explained by the metal replacement of $\mathrm{Fe}^{3+}$ magnetic ions $\left(3 d^{5}, S=5 / 2\right)$ by non-magnetic $\mathrm{Al}^{3+}$ ions $\left(3 d^{0}, S=0\right)$ or $\mathrm{Ga}^{3+}$ ions $\left(3 d^{10}, S=0\right)$. As mentioned previously, $\varepsilon-\mathrm{Fe}_{2} \mathrm{O}_{3}$ is a ferrimagnet with positive sublattice magnetizations at $\mathrm{Fe}_{\mathrm{B}}$ and $\mathrm{Fe}_{\mathrm{C}}$ sites and negative sublattice magnetizations at $\mathrm{Fe}_{\mathrm{A}}$ and $\mathrm{Fe}_{\mathrm{D}}$ sites. With the substitution of $\mathrm{Fe}_{\mathrm{D}}$ site $\mathrm{Fe}^{3+}$ ions with non-magnetic ions, the total magnetization increases, leading to the increase of $M_{\mathrm{s}}$ value. In addition, the non-magnetic ions reduce the superexchange interaction between the magnetic sites, resulting in a decrease of $T_{\mathrm{C}}[26]$.

(a)

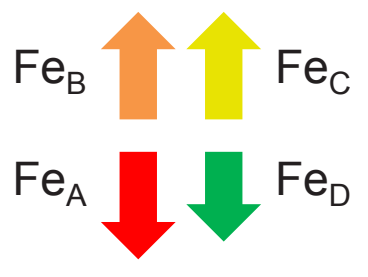

(b)

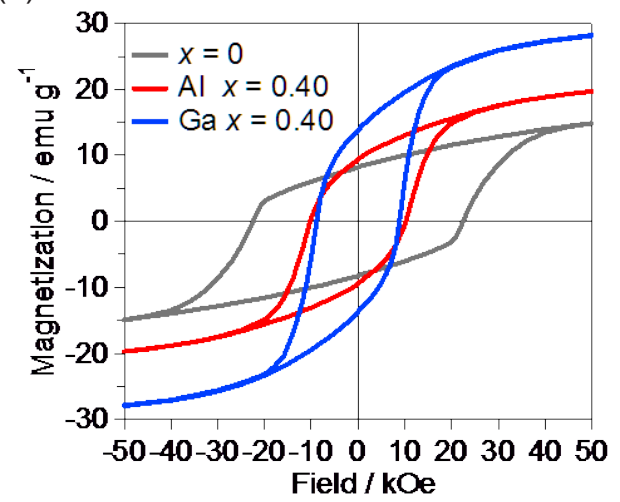

(c)

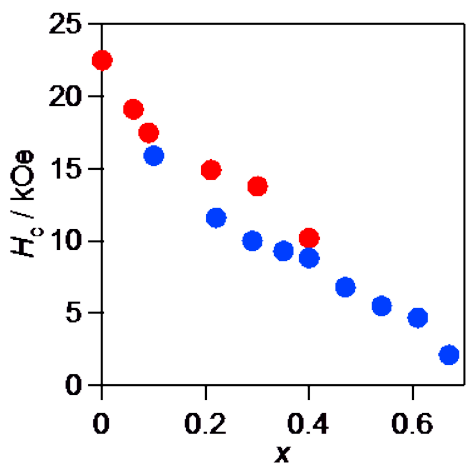

Fig. 3 (a) The magnetic structure of $\varepsilon-\mathrm{Fe}_{2} \mathrm{O}_{3}$. (b) Magnetization versus external magnetic field curve of $\varepsilon$ - $\mathrm{Fe}_{2} \mathrm{O}_{3}$ (gray line), $\varepsilon-\mathrm{Al}_{0.40} \mathrm{Fe}_{1.60} \mathrm{O}_{3}$ (red line), and $\varepsilon-\mathrm{Ga}_{0.40} \mathrm{Fe}_{1.60} \mathrm{O}_{3}$ (blue line) at $300 \mathrm{~K}$. (c) $H_{\mathrm{c}}$ value versus substitution ratio plot. Red circles are $\varepsilon-\mathrm{Al}_{x} \mathrm{Fe}_{2-x} \mathrm{O}_{3}$ and blue circles are $\varepsilon-\mathrm{Ga}_{x} \mathrm{Fe}_{2-x} \mathrm{O}_{3}$.

\section{HIGH-FREQUENCY MILLIMETER WAVE ABSORPTION}

The millimeter wave absorption spectra of $\varepsilon-\mathrm{Ga}_{x} \mathrm{Fe}_{2-x} \mathrm{O}_{3}$ and $\varepsilon-\mathrm{Al}_{x} \mathrm{Fe}_{2-x} \mathrm{O}_{3}$ are shown in Fig. 4. The absorption properties in the millimeter wave region were measured using two methods. Free space electromagnetic wave absorption measurement system was used for the lower frequency region (V-band; 50-75 GHz, and W-band; 75-110 GHz). Ga substituted samples $(x=0.61-0.29)$ were measured in this region, and the powder samples were filled in $30 \mathrm{~mm} \varphi \times$ $10 \mathrm{~mm}$ quartz cell with fill ratios of $c a .40 \%$. As the $x$ value decreased, the absorption frequency shifted higher, i.e., $64 \mathrm{GHz}(x=0.54), 73 \mathrm{GHz}(x=0.47), 84 \mathrm{GHz}(x=0.40), 88 \mathrm{GHz}(x=0.35)$, and $97 \mathrm{GHz}(x=0.29)$. In the case of 
$x=0.67,0.22$, and $0.15 \mathrm{Ga}$ substituted samples, the absorption peaks exceed the measurement range $(50-110 \mathrm{GHz})$. Therefore, hand-made apparatuses for the range of $27-40 \mathrm{GHz}$ and $105-142 \mathrm{GHz}$ were prepared to confirm the absorption frequencies of these materials. As a result, the sample for $x=0.67$ showed an absorption peak at $35 \mathrm{GHz}$, and the absorption frequencies of $x=0.22$ and 0.15 were observed at $115 \mathrm{GHz}$ and $126 \mathrm{GHz}$, respectively.

For the measurement of higher frequency range, terahertz time domain spectroscopy (THz-TDS) measurement system was used. Al substituted samples were measured in this region, and the powder samples were filled in $8 \mathrm{~mm} \times 8 \mathrm{~mm} \times$ $8 \mathrm{~mm}$ paper containers with fill ratios of $c a$. 30\%. The electromagnetic wave absorption spectra are shown in Fig. 4 with red lines. Absorption peaks were observed at $112 \mathrm{GHz}(x=0.40), 125 \mathrm{GHz}(x=0.30), 145 \mathrm{GHz}(x=0.21), 162 \mathrm{GHz}$ $(x=0.09), 172 \mathrm{GHz}(x=0.06)$, and $182 \mathrm{GHz}(x=0)$. Similar to the Ga substituted series, the $f_{\mathrm{r}}$ value decreased with $\mathrm{Al}$ substitution, consistent with the behavior of the $H_{\mathrm{c}}$ value (Fig. 3c).

The mechanism of the observed millimeter wave absorption is explained as the following. Generally, when electromagnetic wave is irradiated into a ferromagnet under zero magnetic field, zero-field ferromagnetic resonance (natural resonance) occurs. The bulk magnetization is tilted away from the magnetic easy-axis by the magnetic component of the electromagnetic wave, and precession of the magnetization occurs around the easy-axis due to gyromagnetic effect. Resonance absorption is observed when this precession frequency coincides with the electromagnetic wave frequency [28]. This resonance frequency $\left(f_{\mathrm{r}}\right)$ is proportional to the magnetocrystalline anisotropy $\left(H_{\mathrm{a}}\right)$ and can be expressed as $f_{\mathrm{r}}=(v / 2 \pi) H_{\mathrm{a}}$, where $v$ is the gyromagnetic ratio. If the sample is consisted of randomly oriented particles with uniaxial magnetic anisotropy, the $H_{\mathrm{a}}$ value is proportional to $H_{\mathrm{c}}$. Therefore, electromagnetic wave absorption at high frequencies is expected with insulating materials exhibiting large coercivity, which is the case for $\varepsilon-\mathrm{Fe}_{2} \mathrm{O}_{3}$ based magnets.

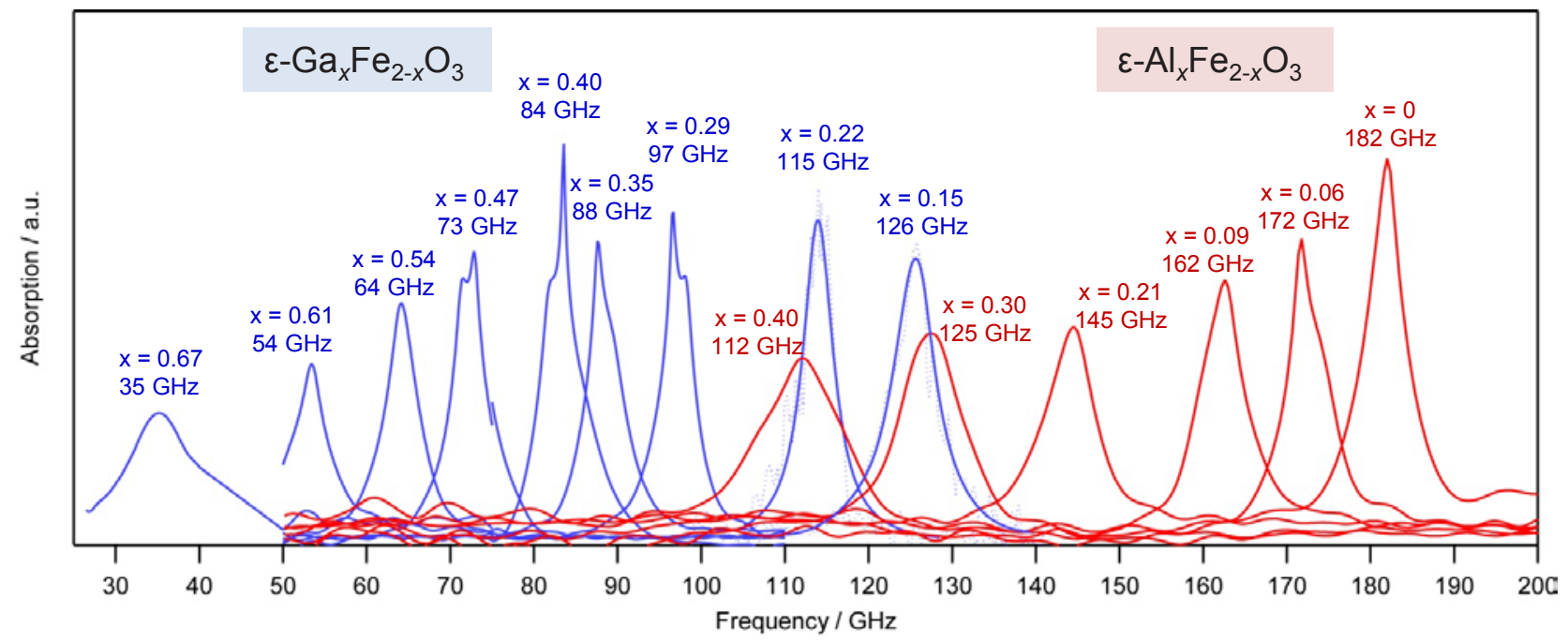

Fig. 4 Millimeter wave absorption spectra of $\varepsilon-\mathrm{Ga}_{x} \mathrm{Fe}_{2-x} \mathrm{O}_{3}$ (blue lines) and $\varepsilon-\mathrm{Al}_{x} \mathrm{Fe}_{2-x} \mathrm{O}_{3}$ (red lines) at room temperature. For Ga substituted $x=0.22$ and 0.15 , the dotted lines represent the experimental data and the solid lines are eye guides.

\section{CONCLUSION}

In this article, millimeter wave absorption properties of $\varepsilon-\mathrm{Fe}_{2} \mathrm{O}_{3}$ and metal substituted $\varepsilon-\mathrm{Fe}_{2} \mathrm{O}_{3}\left(\varepsilon-M_{x} \mathrm{Fe}_{2-x} \mathrm{O}_{3}, M=\mathrm{Al}\right.$ and $\mathrm{Ga}$ ) were described along with the synthesis, crystal structure, and magnetic properties. The $\mathrm{Al}^{3+}$ and $\mathrm{Ga}^{3+}$ ions selectively substituted the tetrahedral sites of the crystal structure, increasing the magnetization and decreasing the coercive field. This leads to the tuning of the resonance frequency of millimeter wave absorption, since the resonance frequency is proportional to the magnetic anisotropy of the material. By Al substitution and Ga substitution, $\varepsilon-\mathrm{Fe}_{2} \mathrm{O}_{3}$ based magnets absorbed millimeter waves covering a wide range of $35-182 \mathrm{GHz}$. Therefore, it has the potential as millimeter wave absorbers for the next generation wireless communications to prevent electromagnetic wave interference problems. Furthermore, this material is based on chemically stable iron oxide $\mathrm{Fe}_{2} \mathrm{O}_{3}$, encouraging the possibility for industrial applications. 


\section{ACKNOWLEDGMENTS}

The present research was supported partly by the Core Research for Evolutional Science and Technology (CREST) program of the Japan Science and Technology Agency (JST), a Grant-in-Aid for Young Scientists (S) from the Japan Society for the Promotion of Science (JSPS), DOWA Technofund, the Asahi Glass Foundation, a Grant for the Global COE Program "Chemistry Innovation through Cooperation of Science and Engineering", Advanced Photon Science Alliance (APSA) from the Ministry of Education, Culture, Sports, Science and Technology of Japan (MEXT), JSPS KAKENHI Grant Number 24850004, Office for Gender Equality, The University of Tokyo, the Cryogenic Research Center, The University of Tokyo, the Center for Nano Lithography \& Analysis, The University of Tokyo, supported by MEXT. M. Y. is grateful to Advanced Leading Graduate Course for Photon Science (ALPS) and JSPS Research Fellowships for Young Scientists. We are grateful to Mr. Y. Kakegawa and Mr. H. Tsunakawa for collecting the TEM images, and Mr. T. Miyazaki and T. Yoshida of DOWA Electronics Materials Co., Ltd. for the valuable discussions.

\section{REFERENCES}

[1] R. M. Cornell and U. Schwertmann, "The Iron Oxide: Structure, Properties, Reactions, Occurrence and Uses", VCH, Weinheim, Germany, 1999.

[2] D. J. Craik, "Magnetic Oxides", John Wiley \& Sons, Ltd, Bristol, UK, 1975.

[3] K. Kato and T. Takei, Trans. Amer. Electrochem. Soc. 57, 297 (1930).

[4] T. Takei, J. Inst. Elect. Eng. Japan, 59, 274 (1939).

[5] M. Sugimoto, J. Phys. 38, 117 (1977).

[6] Y. Yamazaki, J. Jpn. Soc. Powder Powder Metall. 41, 1270 (1994).

[7] T. Taniyama, Y. Kitamoto and Y. Yamazaki, J. Appl. Phys. 89, 7693 (2001).

[8] O. Bomatí-Miguel, L. Mazeina, A. Navrotsky and S. Veintemillas-Verdaguer, Chem. Mater. 20, 591 (2008).

[9] J. Jin, S. Ohkoshi and K. Hashimoto, Adv. Mater. 16, 48 (2004).

[10]S. Ohkoshi, S. Sakurai, J. Jin and K. Hashimoto, J. Appl. Phys. 97, 10K312 (2005).

[11]J. Tuček, R. Zbořil, A. Namai and S. Ohkoshi, Chem. Mater. 22, 6483 (2010).

[12]S. Sakurai, J. Jin, K. Hashimoto and S. Ohkoshi, J. Phys. Soc. Jpn. 74, 1946 (2005).

[13]M. Kurmoo, J.-L. Rehspringer, A. Hutlova, C. D’Orléans, S. Vilminot and C. Estournès, Chem. Mater. 17, 1106 (2005).

[14]M. Gich, C. Frontera, A. Roig, E. Taboada and E. Molins, Chem. Mater. 18, 3889 (2006).

[15]Y.-C. Tseng, N. M. Souza-Neto, D. Haskel, M. Gich, C. Frontera, A. Roig, et al., Phys. Rev. B, 79, 094404 (2009).

[16]S. Sakurai, J. Shimoyama, K. Hashimoto and S. Ohkoshi, Chem. Phys. Lett. 458, 333 (2008).

[17]S. Sakurai, S. Kuroki, H. Tokoro, K. Hashimoto and S. Ohkoshi, Adv. Funct. Mater. 17, 2278 (2007).

[18]J. Tuček, S. Ohkoshi and R. Zbořil, Appl. Phys. Lett. 99, 253108 (2011).

[19]A. Namai, S. Sakurai, M. Nakajima, T. Suemoto, K. Matsumoto, M. Goto, et al., J. Am. Chem. Soc. 131, 1170 (2009).

[20]S. Ohkoshi, S. Kuroki, S. Sakurai, K. Matsumoto, K. Sato and S. Sasaki, Angew. Chem., Int. Ed. 46, 8392 (2007).

[21] A. Namai, M. Yoshikiyo, K. Yamada, S. Sakurai, T. Goto, T. Yoshida, et al., Nat. Commun. 3, 1035 (2012).

[22]J. Jin, K. Hashimoto and S. Ohkoshi, J. Mater. Chem. 15, 1067 (2005).

[23]S. Sakurai, A. Namai, K. Hashimoto and S. Ohkoshi, J. Am. Chem. Soc. 112, 13095 (2009).

[24]A. Namai, S. Sakurai and S. Ohkoshi, J. Appl. Phys. 105, 07B516 (2009).

[25]R. D. Shannon, Acta Cryst. A32, 751 (1976).

[26]S. Ohkoshi, A. Namai and S. Sakurai, J. Phys. Chem. C, 113, 11235 (2009).

[27]M. Yoshikiyo, K. Yamada, A. Namai and S. Ohkoshi, J. Phys. Chem. C, 116, 8688 (2012).

[28]S. Chikazumi, "Physics of Ferromagnetism", Oxford University Press, New York, U.S.A., 1997. 